\title{
Regenerative Braking Technology in Vehicle
}

\author{
Wanqi Li
}

North China Electric Power University Beinong Road No.2, Huilongguan, Changping district, Beijing, China

806185656@qq.com

Keywords: Energy recovery; Regenerative braking system; Energy conversion and storage; Regenerative braking; Control strategy.

\begin{abstract}
Nowadays, the world car ownership is rapidly expanding, and $99.9 \%$ of which are traditional energy vehicles. The energy consumption and environmental pollution pressure it brings has become a global challenge. In this background, energy recovery has become an effective way to ease the pressure of energy and environment. Automotive braking energy has been exploited and motor regenerative braking system has been developed but there are a lot of problems, which need to be solved. In this paper, we review the motor regenerative braking system on the principle of regenerative braking, energy conversion and storage, control strategy and key technologies and so on, at the same time put forward the problems which need to be solved.
\end{abstract}

\section{Introduction}

With the development of industry, the impact of energy on human life, social development is growing. Automobile brings convenience to human life but also cause great burden to energy and the environment. When a running car is put on the brake, its kinetic energy is changed into heat energy being consumed. The braking energy of automobile accounts for about $50 \%$ of the drive energy [1], which only can be converted into thermal energy dissipation by friction, resulting in premature wear of the vehicle braking system. Nowadays, with the increasingly demanding in the car energy consumption and environmental protection, the use of advanced energy recovery technology on automobile brake energy recycling has very important significance. Energy conservation environmental protection has become an inevitable trend in automobile industry.

\section{Theory of Regenerative Braking}

Regenerative braking refers to convert a portion of kinetic energy and potential energy of the automobile into other forms of energy through energy conversion device during deceleration or braking and store the energy in the storage device. The stored energy is used for vehicle lighting systems. In this way, only to achieve the vehicle deceleration and braking, but also effectively reduces the tender oil consumption and pollutant emissions of the vehicle, but also reduces wear of the brake friction plate [2]. The schematic diagram is shown below:

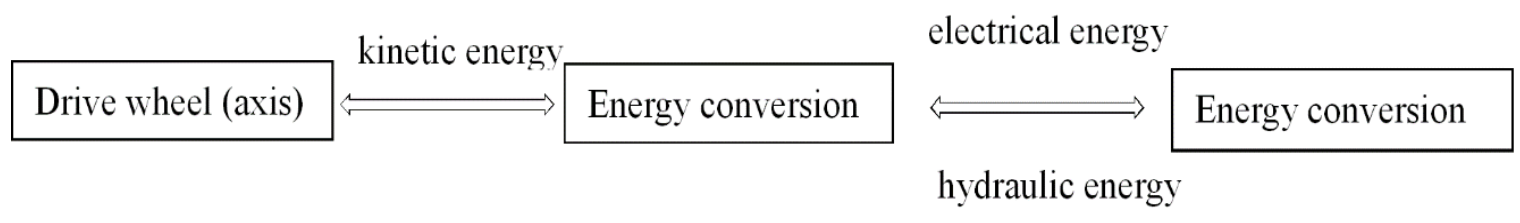

Figure 1. Regenerative braking principle

\section{Regenerative Braking Energy Recovery System}

Energy Conversion Device. In the electric regenerative braking energy storage, energy conversion device converts braking and driving torque and transforms the car inertia kinetic energy into electrical energy, which is a power generation process. In order to recovery and release braking 
energy, the system needs proper transmission device with a motor acts as a generator (regenerative braking motor) and electric motor (drive motor), which cooperates with the clutch to meet the functional requirements [3].

Energy Storage Device. In order to achieve the better recovery and use of braking energy, energy storage system needs to meet the requirements in efficiency, charging and discharging rate, charging times requirements, cost, safety, etc.

(1) Electrochemical batteries. The electrochemical cell is the traditional choice for automotive energy storage, including lead-acid batteries, nickel metal batteries, and lithium batteries, etc. Lead-acid battery has high reliability, reactants, low cost, large range of applicable temperature and current, having been the most widely used in automobile energy storage. But the disadvantages of lead-acid battery as the braking energy storage system is mainly charging speed slow, low circulation service life, etc. Lithium battery is a high capacity rechargeable battery developed in the end of last century, having super performances such as high specific energy, long cycle life and low self-discharge rate, etc. [4].It is a hotspot of research on the energy storage technology all over the world.

(2) Super capacitor. Super capacitor, also called double layer capacitor, is an energy storage device which satisfies the requirement of vehicle real-time changes in energy and power in recent years with the emergence of new electrode materials [5]. The capacity of super capacitor is 2000 to 6000 times of normal capacitor, the discharge current can amount to several thousand amperes, energy density is higher than traditional capacitor nearly one hundred times, with high charge-discharge efficiency, no maintenance and maintenance, and long life of more than a decade.

(3) Flywheel battery. Flywheel battery is a kind of mechanical battery which energy are stored by the kinetic energy of mechanical battery which store energy in the kinetic energy. In recent years, due to the presence of the high strength carbon fiber and glass fiber as well as the development of electromagnetic levitation, superconducting magnetic suspension technology and vacuum technology, linear velocity of the flywheel can reach 100 to $500 \mathrm{~m} / \mathrm{s}$ [6]. Unit mass reserves increase greatly, the motion of the mechanical friction and wind loss is greatly reduced. Thus the flywheel energy storage technology has become one of the highlights in agro-scientific research in the automobile energy storage.

(4) The composite energy storage system. As simply a storage battery is often difficult to adapt to the requirement of automobile energy storage, especially for recycling and utilization of regenerative braking energy of automobile, which needs to consider service life, charging efficiency, cost and other factors, then we can adopt the way of composite energy storage, to achieve maximum energy recovery and energy utilization optimization. Super capacitor has a good fast charge capability and high specific power density, which can provide high peak power assist during acceleration or uphill car, and provide good power to the rapid recovery of the energy during deceleration or braking. Therefore, the composite energy storage systems are mostly adopt super capacitor power battery combination with other applications, and many research institutions at home and abroad are in the study of super capacitors and other power supply to work together in the system.

\section{Auto Control Strategy and Key Technologies}

Control Strategy. Automotive regenerative braking control strategy goal is to fully recovery of braking energy under the condition of ensuring the safety performance and driving comfort requirements, while braking force distribution is the primary issue in the study of control strategy, the design goal is to improve the energy recovery rate and optimization of the driver. At present in the study of motor regenerative braking and hydraulic brake system working together according to the braking force distribution pattern different braking energy recovery system can be divided into parallel braking energy recovery system and tandem braking energy recovery system, and front and rear brake braking force of the hydraulic brake system is not adjustable in the parallel braking energy recovery system while the force is adjustable in the tandem braking energy recovery system [7]. 
Parallel braking energy recovery system is generally based on the traditional automobile brake system to join a brake motor (that is, drive motor for hybrid electric vehicle), and adopt the combination of mechanical brake and regenerative braking system on the drive shaft while traditional mechanical brake on the non-drive shaft. The control strategy is to switch braking mode according to the intensity of the brake [8].

In the tandem braking energy recovery system, the energy control strategy is mainly based on the ideal braking force distribution curve to carry on the design [9], there are the following theories at present [10]: (1) The best braking energy recovery control strategy: To maximize the recovery of braking energy as the goal, use motor regenerative braking as much as possible while ensuring the requirements of the braking deceleration and the front and rear wheel are not lock. The strategy can have high energy recovery rate, but the control system is complex which need to precisely control over braking mechanism of electric power and friction braking force. (2) The best braking performance control strategy: the target is to ensure that the vehicle has the best braking force distribution under the premise of recycling the braking energy.

Key Technologies. At present the key technical problems needed to resolve in the regenerative braking control strategy and mechanical and electrical composite brake braking energy recovery system are: brake stability problems, the adequacy of the braking energy recovery problems, brake pedal stability problems, and composite braking coordination compatibility problems. (1) brake stability: since the speed have a great influence on the electric braking torque (that is, the regenerative braking torque), its braking process is different from which with only the friction braking of the braking system. (2) the adequacy of the braking energy recovery: energy recovery capability is affected by battery characteristics, the electrical operating characteristics, the charging speed and other factors. Due to the braking energy recycling often existed problem such as charging and fast charging, makes the motor and battery work auspicious is complicated, so through improved motor control technology, battery energy storage technology and the use of advanced energy storage way to improve the charging efficiency of the system is the key to ensure the braking energy recycling sufficiency. (3) brake pedal stability: electric braking torque as an auxiliary braking torque will affect the brake pedal and driving comfort, and need to optimize the size of the electric braking torque control to make the car brake with conventional automobile brake system brake feel the same. (4) composite braking coordination compatibility: in order to fully realize energy recovery, regenerative braking system needs to be compatible with conventional braking system, ABS system good coordination, so reasonable design the comprehensive control strategy of electric mechanism regulated torque and the brake torque adjustment to realize the coordinated control is necessary.

\section{Conclusion}

Motor regenerative braking technology is a novel technology for our country, and because the conventional hydraulic braking system provides a large braking force, stable braking performance, mature technology, low cost, etc. Hydraulic braking system often cannot be replaced. The combination of regenerative braking and conventional hydraulic brake technology is to solve one of the most key problems of regenerative braking.

\section{References}

[1] Eiji Nakamura, Masayuki soga, Akira Sakai. Development of Electronically Controlled Brake System for Hybrid Vehicle [J]. SAE paper, 2002-01-0300.

[2] Z.Y. Zhang, B.C. Zhang. Review on Vehicle Braking Energy Recovery and Reuse Technology [A]. Energy Conservation Thechnology, 2010, 5(3):213-217. (In Chinese).

[3] B.Liu, J.H. Liu and G.G.Qi. The electric car braking energy recovery control strategy research[J]. Electronic Technology Applications, 2004 (1):33-36.(In Chinese).

[4] Y.Yu , M Su and Y.Sun.Simulation of Braking Energy Recovery System and Design of 
Controller for EV[J].Journal of Instrument,2014,06:1261-1268.(In Chinese).

[5] F.Zhao, Q.Z.Chen and Z.Liu. Experimental research of vehicle coasting energy based on ultra-capacitor[J]. Journal of Chinese Agricultural Mechanization, 2015, 02: 215-218. (In Chinese).

[6] X.M.Cheng,F.C.Shun.Overview of energy storage technology for electric vehicles[J].Chinese Journal of Power Sources, 2001,01:47-52.(In Chinese).

[7] Q.Z.Chen.Research on the stability and brake padel comfort of vehicle regeneration braking[D].Jiangsu University,2008.

[8] B.H.Wang, J.W. Zhang, Y.G. Luo. A study on Regenerative Braking for Parallel Hybrid Electric Bus[J]. Automotive Engineering, 2005, 06:648-651.

[9] J.Z.Zhang, J.L.Xue and X.Lu. Series Regenerative Braking Technique for Hybird Electric Buses[J]. Journal of Mechanical Engineering, 2009, 06:102-106.

[10]G.F.Li, Y.Lin and H.W.He. Regenerative Braking Control Strategy for Electric Vehicle [J]. Transaction of Beijing Institute of Technology, 2009, 06:520-524. 